\title{
On the development of flight-test equipment in relation to the aircraft spin
}

\author{
C J BENNETT \& N J LAWSON \\ National Flying Laboratory Centre \\ School of Aerospace, Transport and Manufacturing \\ Cranfield University \\ C.J.Bennett@Cranfield.ac.uk
}

\begin{abstract}
A review of the development of flight test equipment throughout aviation history is presented, focusing specifically on the stall spin. The primitive, yet, ingenious solutions devised in the early twentieth century by the pioneers of this field, paved the way for the advancement in knowledge of the complex aerodynamic properties inherent during a spin. Both in Britain and the US, the dangers associated with stalling and spinning were acknowledged shortly after the birth of aviation, with pilots and academics alike seeking to investigate the causes. Initially, the goal was to design safer aircraft, with more predictable handling, dynamic manoeuvrability, and precise controllability. Both nations were able to independently develop equipment packs which were to become standard for airborne investigations of the spin and other manoeuvres in the following years. These early studies laid the foundations on which we're still building today, now using state-of-the-art technology to enhance our knowledge of spin dynamics ever further.
\end{abstract}

\section{INTRODUCTION}

\section{Definition of the stall spin}

A spin is defined as an auto-rotating decent of a stalled aircraft in a helical pattern about the vertical axis. The situation occurs when the critical angle of attack is exceeded, leading to flow separation on the upper surface of the wings, and a reduction in lift. Under these conditions, an imbalance of load on the wings causes one wing to stall before the other. This action initiates the spin and in turn leads to a rapid decent of the aircraft [1].

There are 3 distinct stages of the stall spin [2], as depicted in Fig. 11 The first, often referred to as the incipient stage, is the most complex aerodynamically. The incipient stage is the transition from straight and level, stalled, flight, into the auto-rotating vertical decent. The second stage, commonly referred to as the developed stage, is reached once the spin frequency and radius has stabilised. It is worth noting that the wings remain stalled throughout the incipient and developed stages. Finally, the pilot takes the appropriate action to regain control of the aircraft in the recovery stage.

A spin is characterised by several important features: spin frequency (number of rotations per second), spin radius (distance between the aircraft centre of gravity and the vertical spin axis), and the angle of attack (angle between the aerofoil chord and the relative airflow). In general, these characteristics coincide, for example, a flat spin (ie. a spin with close to $90^{\circ}$ angle of attack) tends to have a tighter radius and a faster frequency. 


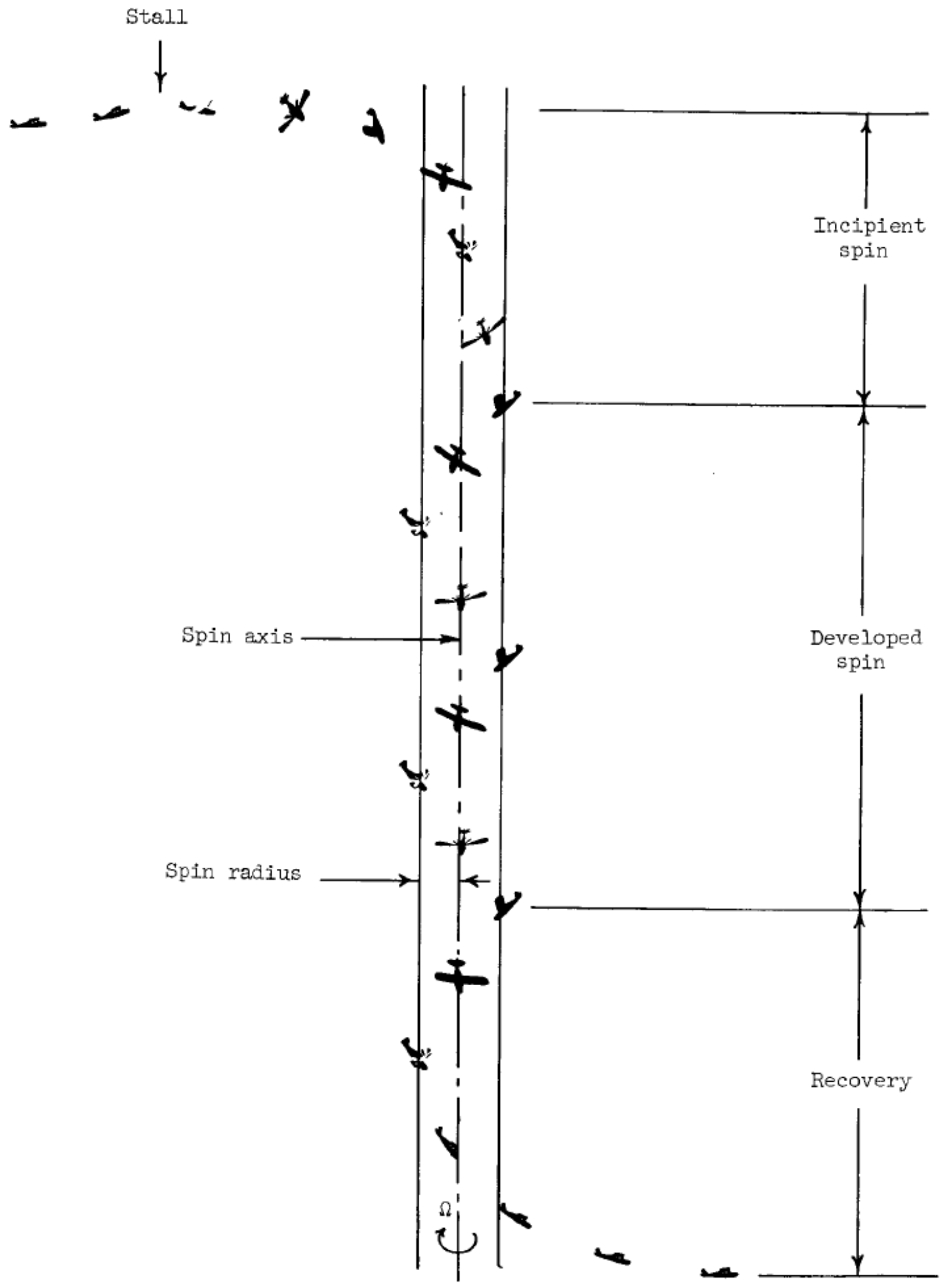

Figure 1: The full spin trajectory as depicted by Bowman [3]. 


\section{Pilot's perspective}

From the pilot's perspective, a spin is a dangerous scenario to experience due to the rapid decent rate and altitude required to recover. A high proportion of light aircraft accidents are attributed to stalling, or a subsequent spin, at insufficient altitude [4]. As a result, spinning is often feared by the inexperienced pilot who learns to avoid the onset of a stall rather than gain experience of how to recover from it.

However, tactical, training, and aerobatic aircraft are designed in such a way that recovery from a spin is possible, if the pilot applies the correct technique. Therefore, pilots of these categories of aircraft are required to demonstrate effective recovery from any uncontrolled flight manoeuvre, including a fully developed spin. A spin is performed by decelerating the aircraft by reducing the power, and gradually pitching the nose of the aircraft up to maintain level flight. As the critical angle of attack approaches, the pilot will feel the airflow begin to detach from the wings - this is called buffeting. At this stage, the pilot makes a full rudder input either to the left or right to initiate the spin, while continuing to hold the stick fully back. Holding the controls fixed in this position, the spin will soon stabilise in rotation rate and angle of attack. There are a number of recommended recovery techniques, depending on the aircraft type, but the typical procedure is as follows [5]:

- Reduce power to idle;

- Centralise the ailerons;

- Apply full opposite rudder;

- Apply forward elevator.

Once a suitable airspeed has been reached from the subsequent dive, the aircraft may be returned to straight and level flight. In normal flight however, it is imperative that a pilot is able to identify the initial stages of a spin, so that he may take the appropriate action to recover before it develops. Furthermore, it is important that the pilot recognises the difference between a stall spin and a spiral dive.

Over the years, the aircraft spin has been the subject of numerous research projects, tests and investigations, a summary of which is given in this paper. Particular attention is paid to the equipment and methodologies developed to facilitate flight-testing of spins.

\section{Historical Background - Events Leading up to the First Flight-Tests of the Spin}

The earliest experience of an aeroplane spin, and subsequent acknowledgement of its dangers, is thought to have been as early as 1909 [6]. Of course, since the dawn of aviation, the aerodynamic conditions necessary for the initiation of a spin were apparent, but with flying taking place just above the ground, characteristics of the spin were not allowed to develop, and therefore were not identified as such. Despite this, the aerodynamic features leading to wing stall, and hence a reduction in lift, were understood: the Wright brothers approximated that $90 \%$ of all fatal accidents in these early days of aviation were attributed to stalling.

In its first annual report in 1910 [7], the British Advisory Committee for Aeronautics (ACA), later re-named the Aeronautical Research Committee (ARC) in 1919, identified spinning as a dangerous scenario, and hence a topic which should be fully investigated. This led to a number of 
pioneering studies on the subject in the decade which followed, combining aspects of theoretical calculations, experimental investigations, and simple flight-tests. Much like many other areas of technological development in this period of history, progress was accelerated as a result of, and in response to, the First World War.

In 1912, the first recovery from a spin is attributed to Wilfred Parke [8], a Lieutenant in the Royal Navy who also worked as a flying instructor at Hendon Aerodrome while off duty. Following a lengthy endurance trial in an Avro G bi-plane, Parke found himself in trouble as he descended into Lark Hill Airforce Base in the south-west of England. Parke managed to recover just a few feet above the ground by applying full rudder to oppose the yawing moment of the aircraft, and pitching down to reduce the angle of attack. This technique, known as "Parke's dive" ever since, quickly became the standard approach to recovery, a skill still practised by pilots today.

Shortly after this, the first deliberate spin and recovery is thought to have been performed by Sqn Ldr Brooke in 1915 at Killingholme in the north-east of England using Park's technique, although many other pilots began demonstrating spins in the period 1915-1917 [6]. Despite this, the complex dynamics of a spin and the factors affecting a particular aircraft's spin characteristics, were only just beginning to be understood. Aircraft were not designed to facilitate adequate spin recovery like they are nowadays, and so the behaviour of some aircraft was unpredictable and, frankly, dangerous. Many aircraft were lost in this period, as well as several experienced pilots.

Perhaps in response to the dangers faced by pilots when investigating spinning in the air, more emphasis was put on developing experimental model testing and theoretical predictions. The mathematical approach was developing at a rapid rate and, thanks to the pioneering work of the ACA in particular [9, 10, 11], important characteristics of the spin could be predicted. However, it wasn't until several years later that the theory could be compared to scale model testing.

The first rotating balance for spin testing of aeroplane models was developed in 1920 at the Royal Aircraft Establishment (RAE) at Farnborough Airport, Wiltshire. Amongst other studies, experiments on a British Aerial Transport Company (BAT) Bantam fighter model lead to the publication of two extensive ARC Reports and Memoranda (R\&M) by Irving et al. [12, 13]. This work was in direct response to several previous reports which described the aircraft in question entering a "flat spin". In perhaps the first documented use of the term, the flat spin was characterised by a fast rotation rate, around 1 spin per second, a spin radius of only a few feet, and almost impossible to recover from. The subsequent model testing was aimed at revising the design of the tail section of the aircraft to curtail this harsh behaviour. The experimental studies carried out at Farnborough, as well as similar rotating balance investigations at the National Physical Laboratory (NPL) in London, were analysed in the context of the ever developing theory. However here, a focus on the evolution of flight-test methodology and equipment is presented.

Summarising the findings in this early period, the ARC R\&Ms 1000 and 1001 [14, 15] are a significant milestone in spin research. Key results from all other publications to date were compiled and complimented with new findings. However, it was noted that due to the primitive nature of the aircraft's instruments and flight-test apparatus, comparisons with theoretical calculations and spin rig tests were inconclusive. Now that this research was beginning to shape aircraft design, development of flight-test equipment and methodologies were required to solidify any predicted characteristics.

Section $\Pi$ outlines the development of flight-test equipment for spin analysis, from Lindemann's first documented test, to the present day. 


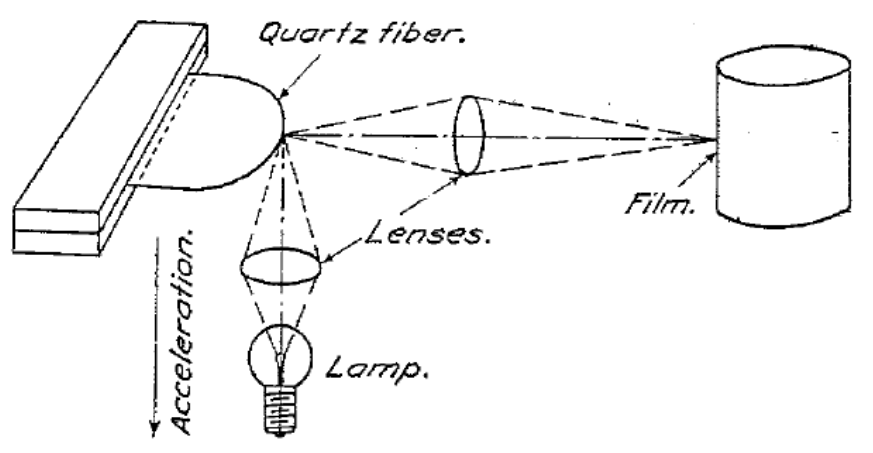

R. A.F. ACCELEROMETER

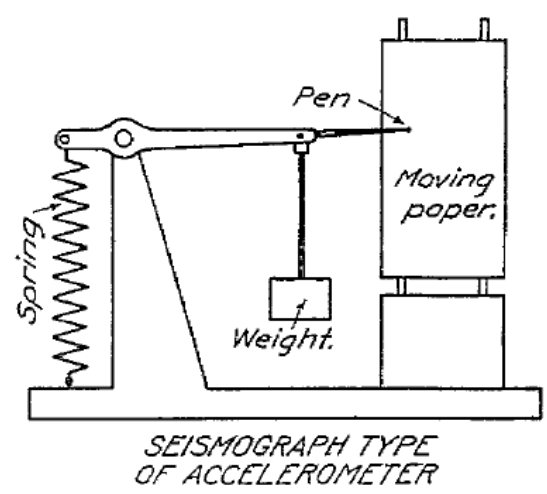

Figure 2: Sketches of two early accelerometer designs.

\section{The Development Race - Advances in Flight-Test EQUIPMENT IN BRITAIN AND THE US}

The first flight-test investigations of spinning were conducted at Farnborough Airfield by Lindemann in 1918 for a publication mentioned in the previous section. Lindemann, a German-born British scientist early in his influential career, had developed a mathematical approach to predict particular features of the spin. It is thought that he learned to fly in just a few months specifically to carry out flight-tests to evaluate his theories. Recording his findings by hand, and using crude instruments and equipment, Lindemann performed spins above a camera in 2 different Royal Airforce Factory bi-planes. A spin frequency of $0.25 \mathrm{~Hz}$ (ie. 4 secs per turn), and a spin radius of around $6 \mathrm{~m}$ were seen. A comparison of his theoretical and flight test results was presented in this pioneering paper [9], showing reasonable agreement.

Spin data gathered by Lindemann [9] was found mainly from the standard aircraft instruments, for example, the rate of decent was measured by the altimeter and a stopwatch. Furthermore, an approximate aircraft attitude was obtained from the standard bubble levels on-board. Lindemann had, however, developed his own instrument to measure normal acceleration. The seismograph-type apparatus essentially consisted of a mass which compressed a spring under load, in turn moving a pen which recorded traces on a moving reel of paper, see the right-hand sketch in Fig. 2. The accelerometer recordings were correlated with airspeed indicator (ASI) readings. However, due to the high angle of incidence during a spin, the ASI did not give reliable readings during the manoeuvre. Therefore, additional dynamic pressure heads were installed at an angle of $30^{\circ}$, the angle typically encountered during the spins in these particular aircraft. Attempts were also made to measure the angle of incidence directly by extending out a rod from the wing strut, with a length of tape attached to the end. It was hoped that, in flight, the tape would align itself with the oncoming free stream of air and hence reveal the angle of incidence to the pilot. However, it was concluded that the tape fluttered too much to make any more than a basic estimation.

This idea was refined a number of years later by Flt Lt Haslam who was interested in visualising the direction of the airflow around the wings under stalled conditions [16, 17]. Haslam attached strips of fabric to the trailing edges of the lower wings of his bi-plane. He observed that 

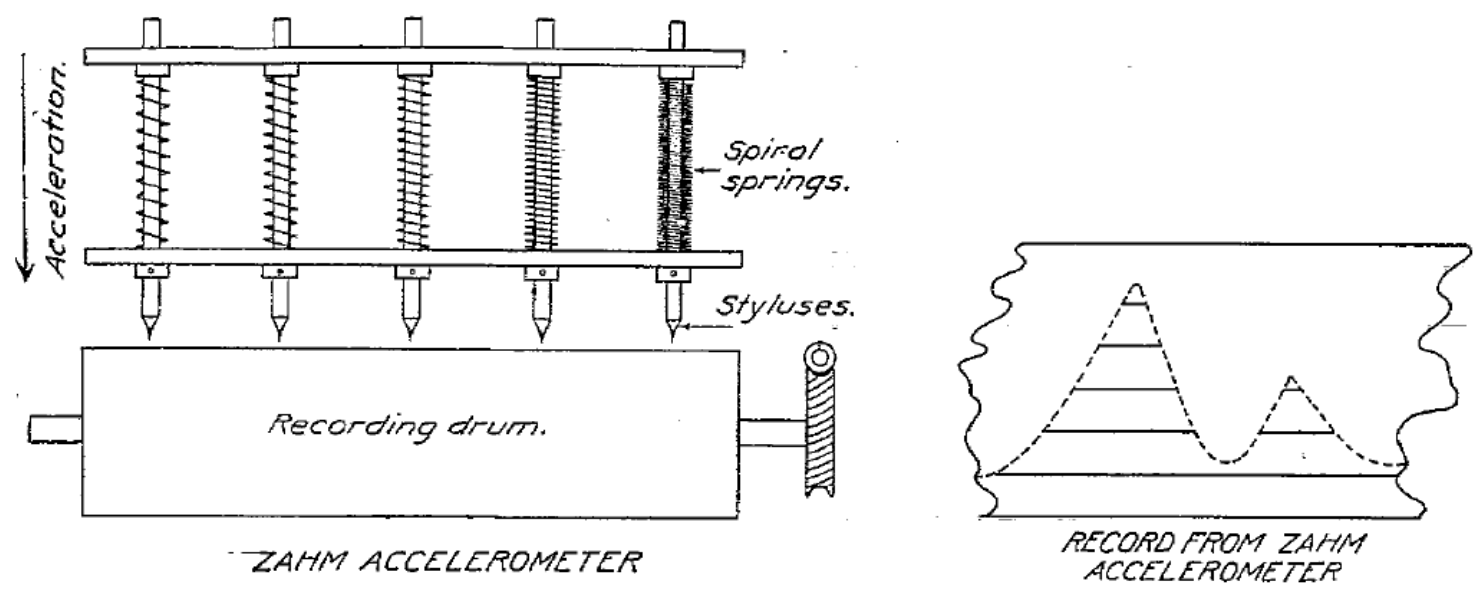

Figure 3: Sketch of the Zahm accelerometer [18].

under pre-stall conditions the cloth streamed out rearwards as expected, but when stalled, the cloth lay forwards, flat against the wing, fluttering sporadically. These tests prompted his idea to use many small wool tufts completely covering the aerofoil section to gain a more comprehensive understanding of the airflow, a technique still used today.

Independent research regarding spin flight testing in the US, was also leading to developments in accelerometer design. A revised version of Lindemann's accelerometer was implemented by Zahm [18], who, in that period of his illustrious career, was director of the US Navy Aerodynamical Laboratory. The design comprised of numerous styluses fixed above a moving strip of paper. The styluses were suspended with springs of increasing tension so that as a certain acceleration is exceeded, the corresponding stylus would be brought into contact with the paper. The end points of the recorded lines could be joined to give a continuous curve, see Fig. 3. The disadvantages of this method is that the resolution of the recorded data depends upon the number of styluses, which is obviously impractical.

In the years that followed, Norton, a pioneering engineer working at NACA, took over Zahm's mantle stateside and was somewhat prolific in the development of a number of flight test apparatus, initially focusing on air speed indicators (ASI). Following experiments using a ToussaintLepere ASI [19] which yielded unsatisfactory results (accurate to within 26\%), he set about redesigning the instrument [20], see Fig. 4 The design consisted of a metal diaphragm which deflected when exposed to the pressure difference of a pitot-static head. The motion was recorded optically through a lens onto a reel of film. Despite the poor quality of the lens providing a low resolution trace, the airspeed recordings were found to be within $2 \%$ of the maximum when compared to water column experiments. Norton had clearly succeeded in improving Toussaint and Lepere's design.

Next, in response to requests from aircraft designers to analyse the stresses on an airframe during a manoeuvre, Norton set about designing an accelerometer [21]. As seen in the sketch in Fig. 5. the design incorporated a flat steel spring fixed at one end. The deflection of the spring under load, in turn, caused a mirror to rotate. A beam of light, reflected from this mirror, was projected onto a moving film. Crucially however, Norton ingeniously used an electromagnet to dampen the springs vibrational resonances. The accelerometer was found to be accurate to 


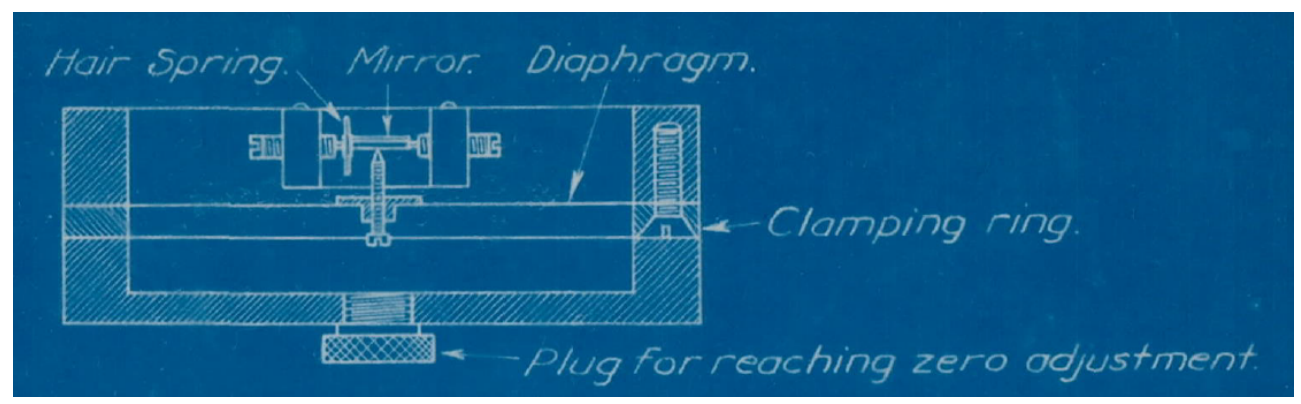

Figure 4: Sketch of Norton's airspeed meter design [20].

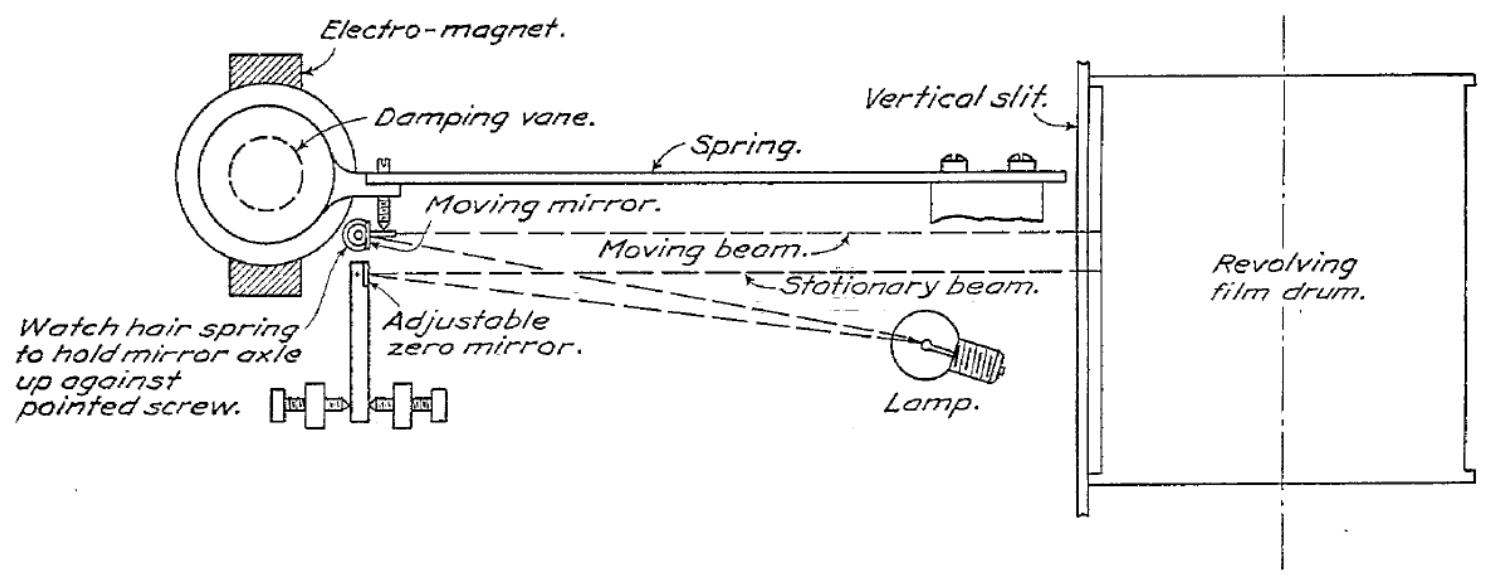

Figure 5: Sketch of Norton's accelerometer design [21].

within $0.01 \mathrm{~g}$ when the acceleration was in the normal plane only, however, the reliability of the readings was severely reduced when accelerations in other planes were introduced.

Meanwhile, back in the UK, the RAF was developing what became a standard instrument pack for flight-tests, one component of which was two separate accelerometers giving normal and lateral g-loadings. The new accelerometer design, replacing Lindemann's original spring and mass assembly, comprised of a highly sensitive semi-circular section of quartz fibre, illuminated by a lamp, see the left-hand sketch in Fig. 2. Under load, the fibre would deflect and it's movement recorded onto a moving film for later analysis. Although accurate to approximately $0.1 \mathrm{~g}$, this was limited to when the accelerations occurred in the normal and lateral directions only, similar to the case of Norton's design [21]. Norton et al. went on to test the two different designs by performing a loop in a JN2 aircraft [22]. It was found that the RAF accelerometer was accurate to $0.23 \mathrm{~g}$ whereas the NACA design was accurate to within $0.002 \mathrm{~g}$. However, the susceptibility of both designs to accelerations in other planes was confirmed. It was also concluded that for best accuracy, the accelerometer of choice should be located as close to the aircraft's centre of gravity as possible.

The RAF standard instrument pack also included control position recorders. Pens which were physically linked to the control surfaces with a series of pulleys and levers, recorded traces on paper reels. Not to be outdone, Norton also designed a NACA control position recorder [23], 


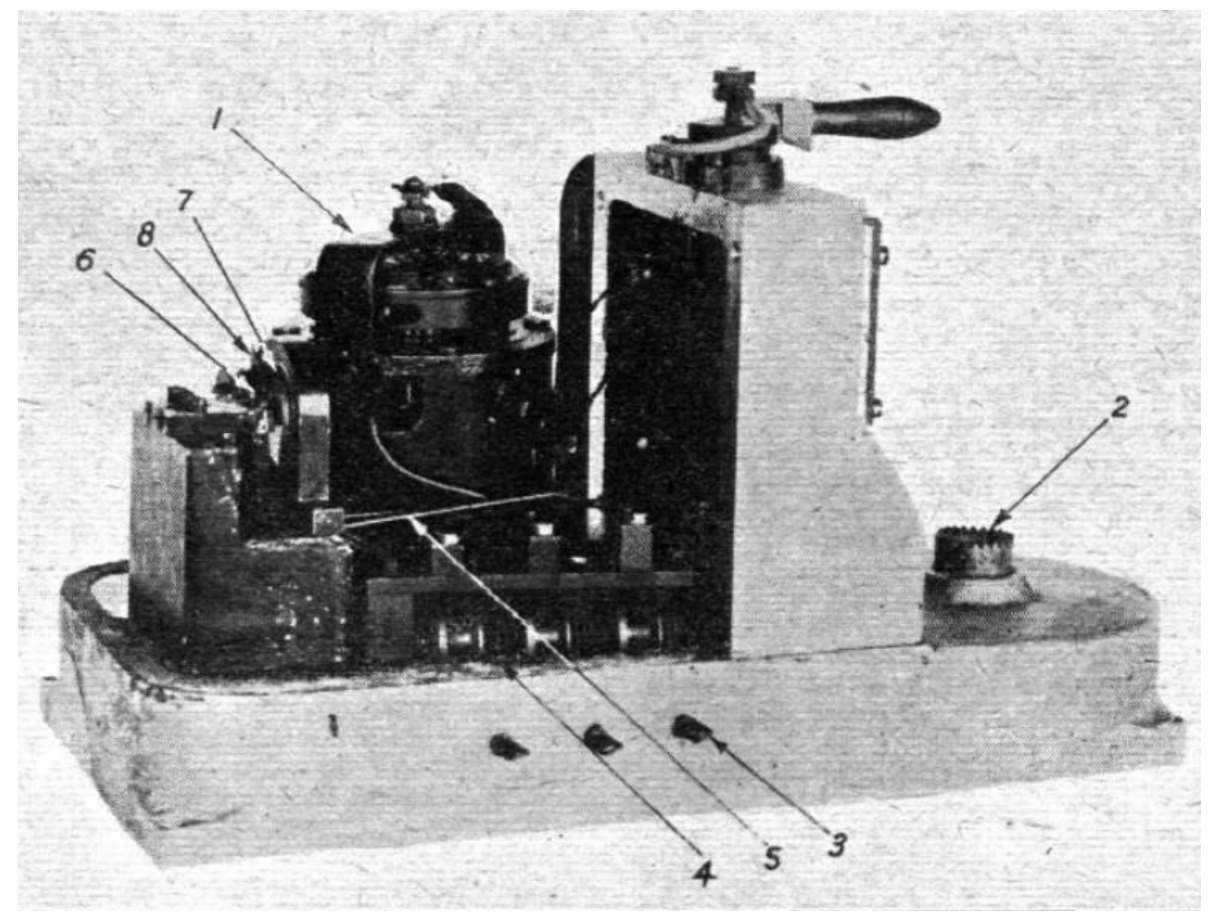

Figure 6: Sketch of Norton's control position recorder [23].

see Fig. 6. The motion of the controls were transmitted to the instrument via cords which wrap around 3 drums. The motion of the drums was transmitted by a series of levers to three mirrors which reflect a beam of light on to a film through a lens. A shutter of different speeds would make one line dotted and one dashed so that they can be distinguished.

Finally, three gyroscopic rate-of-turn indicators were also included in the RAF standard instrument pack which allowed the velocity of rotation about each of the three principal axes to be recorded accurately as in, for example, the Fokker flight tests by Hardy [24]. The instrument comprised of three gyroscopes driven electrically at 18,000 rpm fitted to a base plate at right angles and suspended in a neutral position by springs. As the orientation of the axis of rotation of the gyroscopes changed during flight, the corresponding springs would deflect. This deflection is transferred via an arm to a stylus which reflects a beam of light from a mirror, through a lens, and on to a film. The angular velocity of the aircraft is calculated based on a simple proportional relationship to the recorded spring deflections. These recordings were synchronised with the other standard instrument recordings with a clock-timer.

With the development of the NACA angular velocity recorder by Reid, [25], the US also had a capable set of flight test instruments: The NACA airspeed meter [20], accelerometer [21, 22], control position recorder [23], and the angular velocity recorder [25]. Reid's design worked in very much the same way as the RAF recorder, see Fig. 7, with Reid approximating that the instrument was accurate to $\pm 0.01 \mathrm{rad} / \mathrm{sec}$. He also states the accuracy of the other instruments used for the test as $\pm 2 \mathrm{mph}$ for the airspeed meter, $\pm 0.05 \mathrm{~g}$ for the accelerometer, and $\pm 1 \%$ for the control angles. Again, aimed at refining the aircraft's design, flight tests of the spin were performed in a Curtiss JN-4H. It was found that the maximum angular velocity about the $\mathrm{x}$-axis 


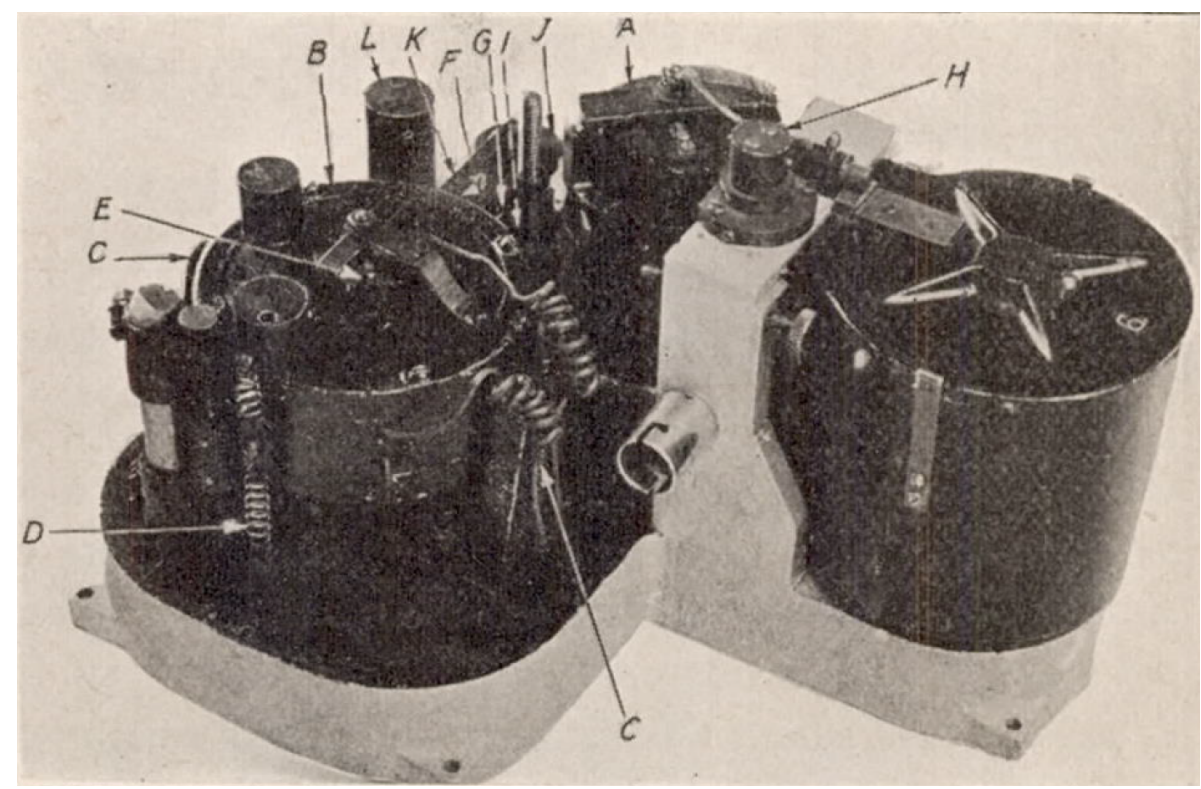

Figure 7: Photograph of the NACA angular velocity recorder [25].

during the spin trials was $2.43 \mathrm{rads} / \mathrm{sec}$, corresponding to a fairly typical spin frequency of 0.39 $\mathrm{Hz}$, even in terms of modern aircraft.

Reid also went one better with the accelerometer design [26]. Using the same type of equipment as Norton [21, 22] which could only measure acceleration in the normal axis, Reid developed an instrument capable of measuring accelerations in three mutually perpendicular directions. Shutters on the individual lenses would open and close at different timing intervals yielding traces of solid, dotted, and dashed lines on the film. Brown [27] showed that the NACA instrument recordings could all be synchronised using an electric chronometer operated lamp, which flashed at regular intervals, see Fig. 8 . The vertical timing lines on each of the film traces allowed the data to be matched up.

A further refinement of the NACA control position recorder was designed by Ronan [28]. Based on the design by Norton [23], Ronan's instrument had an improved mechanism and allowed a wider range of recording at a higher quoted degree of accuracy to within $1 / 5^{\circ}$.

A further significant development in spin research was the design of a reliable altimeter, required to investigate the height loss during a spin. Until the invention of the barometric altimeter in 1928 by Paul Kollsman, aircraft were sometimes fitted with the radio altimeter designed by Lloyd Espenschied. The radio altimeter worked by transmitting a beam of radio waves to the ground and analysing the time taken for the reflection to be received back at the aircraft. This method differed to the new barometric altimeter since it gave pilots their height above the ground in the current location. Kollsman's barometric altimeter, initially rejected by large corporations, was built under the name of his own company and sold to the US navy in 1929. Testing of the new instrument, as conducted by Nesbit [29] for example, demonstrated the accuracy and reliability of the design. The barometric altimeter soon became standard issue in most aircraft, and continues to be used today.

It is also worth noting that spin investigations of this period were also utilising cinemato- 


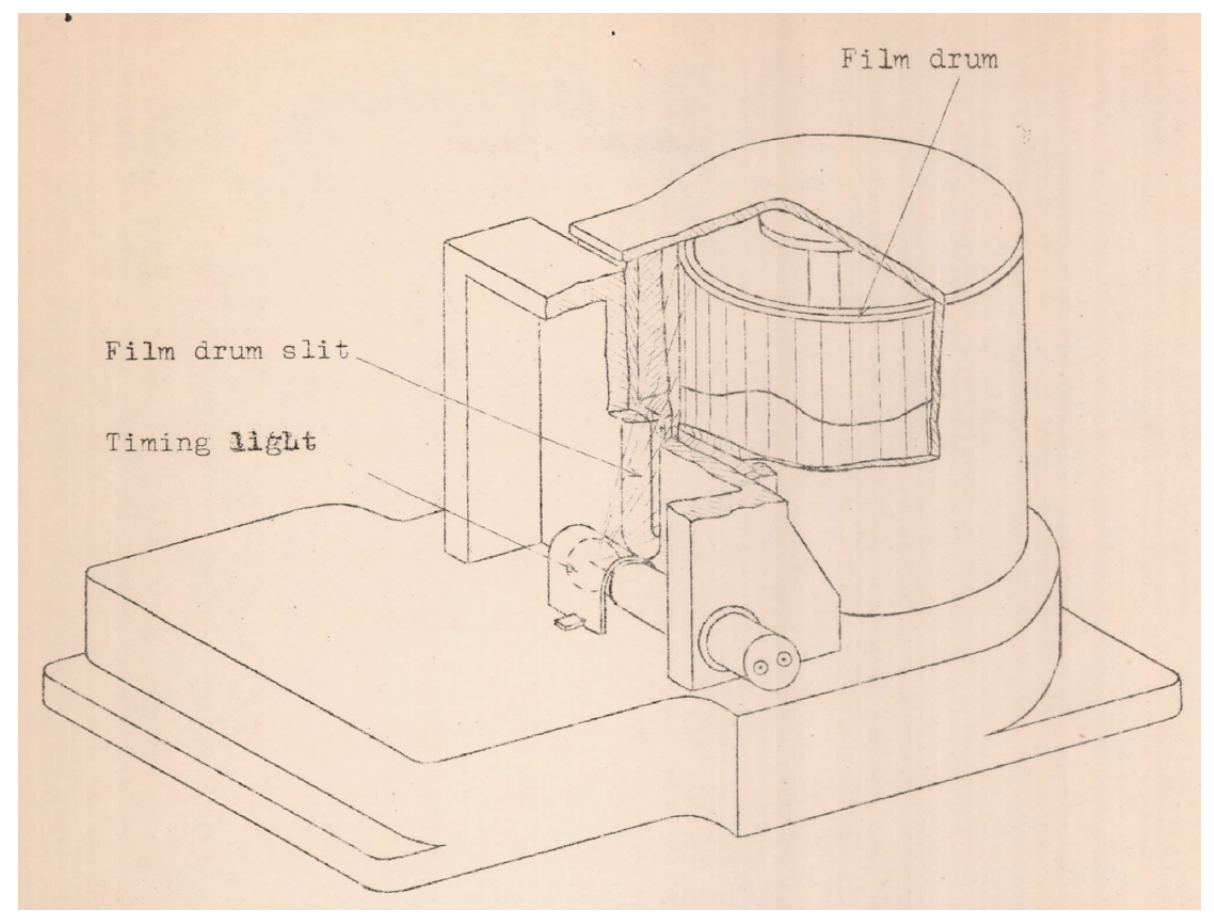

Figure 8: Diagram of the set-up of the synchronisation light pulse [27].

graphic methods. For example, two separate papers documenting observations captured on a video recording of an aircraft spin were published in the German Journal of Aeronautical Engineering and Engine Aviation in 1929 [30, 31]. Although informative, these tests were not considered to fully encapsulate the aircraft's behaviour in such a complex dynamic manoeuvre. Furthermore, with the development of the pinhole cine-camera, research groups began mounting these matchbox sized cameras on the wings to more accurately determine the rate of rotation and also, if the sun was in shot, the angle of incidence [32]. This enabled the angle of incidence readings from the accelerometer, which in the past had sometimes proved unreliable, to be cross checked.

Vanes for recording angles of attack and sideslip were also becoming standard issue at this time, although their readings were regarded only as an indication due to the recognised influence on them by the aircraft itself, as the air flows over it's surfaces [24].

In general, this early flight test equipment was cumbersome and heavy. This meant that carrying it would often shift the aircraft's centre of gravity rearwards, enhancing its instability and unpredictability in a spin. Therefore, the results obtained from these methods were not strictly representative of the unmodified aircraft's spin behaviour and recovery performance.

Despite the recognised limitations of the RAF and NACA standard equipment packs, these instruments were utilised by a number of research groups and formed the basis of a number of key flight-test publications, initially regarding stalled flight only [33, 34, 35] but later in full spin tests [36, 37, 38, 39, 40]. The standard instrument pack had therefore led to significant advances in flight-test capability, and several milestone papers were published as a result. Clearly, this was a major development in spin research and the results of these early flight tests, summarised in 
the following section, were beginning to have a dramatic effect on aircraft design, as well as pilot training.

\section{Results From Early Spin Trials}

Using the RAF standard equipment pack in conjunction with standard aircraft instruments, Wright [36] recorded 11 parameters for a left-hand spin in a Bristol fighter with five turns, synchronised over a 30 second time period, see Fig. 9 . All of the tests were performed with the stick fully back, full rudder in the corresponding spin direction, and with neutral aileron (referred to as a 'normal' spin) as shown by the control position traces in Fig. 9. The results show that the roll rate changes quickly in the incipient stage of the spin and stabilises almost immediately in the developed stage. The yaw rate is seen to steadily increase throughout the 5 turns before the recovery is initiated by the pilot. The pitch rate, however, displays oscillatory behaviour in most cases and, although slightly damped, did not stabilise before the recovery. Oscillations in pitch rate and other parameters were thought to be caused by the spin entry technique, although this theory was not definitively proven.

Spin trials were also underway in the US using the NACA equipment, initially regarding the VE-7 and NY-1 biplanes. Soule and Scudder [37] recorded traces of 5 parameters, see Fig. 10. as well as the altitude, read by the pilot from a barometric altimeter. Previous scale model free flight tests of these aircraft at Langley Research Centre had been shown to have two distinct disadvantages [41]. Firstly, the scaled size of the models (roughly $1 \mathrm{~m}$ wingspan) were not large enough to contain instruments, and so photographic evidence was all that could be collected. Secondly, the scale effect errors of the tests were unknown. Therefore, it was hoped that flight test methodology adopted by Soule and Scudder [37] would not only help to understand the flight path and motion of an aircraft during a spin, but also the forces and moments acting on the aircraft. Results regarding the NY-1 aircraft showed an average spin frequency of approximately $0.39 \mathrm{~Hz}$ for left-hand spins and $0.41 \mathrm{~Hz}$ for right-hand spins. The aircraft also exhibited a tighter spin radius for left hand spins, approximately $1.40 \mathrm{~m}$ compared to $1.55 \mathrm{~m}$ for right-hand spins. Clearly, the yawing effect of the propeller had been identified and it's effects on the spin characteristics had been shown. In general, the results presented by Soule and Scudder showed consistency, despite the obvious oscillations in a number of parameters as in Wright's tests [36]. Finally, it was concluded that the accelerometers should be enclosed in a temperature controlled compartment to improve the accuracy of the readings. With minor adjustments, this flight test methodology was deemed feasible and suitable for further testing.

As an extension of this work, Scudder then went on to investigate the effects of mass distribution on the spin characteristics of both the NY-1 [38] and XN2Y-1 aircraft [39]. Ballast, in the form of containers of lead shot, were positioned at various locations along the aircraft's longitudinal axis to alter the centre of gravity position. With this set-up, the pilot could release the ballast using a lever should he be unable to recover from a spin. Now using an accelerometer housed in a temperature controlled box, the accuracy of the acceleration data was found to be within $0.05 \mathrm{~g}$ of the corresponding wind tunnel data. The other flight-test parameters also showed good agreement with the wind tunnel tests. By altering the mass distribution, the range of spin frequencies recorded in the NY-1 were between 0.27 and $0.54 \mathrm{~Hz}$, corresponding to spin radii between 0.85 and $3.05 \mathrm{~m}$, and for the $\mathrm{XN} 2 \mathrm{Y}-1$, spin frequencies in the range $0.49-0.7 \mathrm{~Hz}$ corresponded to spin radii of $0.29-1.16 \mathrm{~m}$. It was found that, in the case of the NY-1, significantly increasing the wing loading resulted in only a slight change in recorded spin frequency. These results are consistent 


\section{RECORDS OF A LEFT HAND SPIN. (N०8.)}
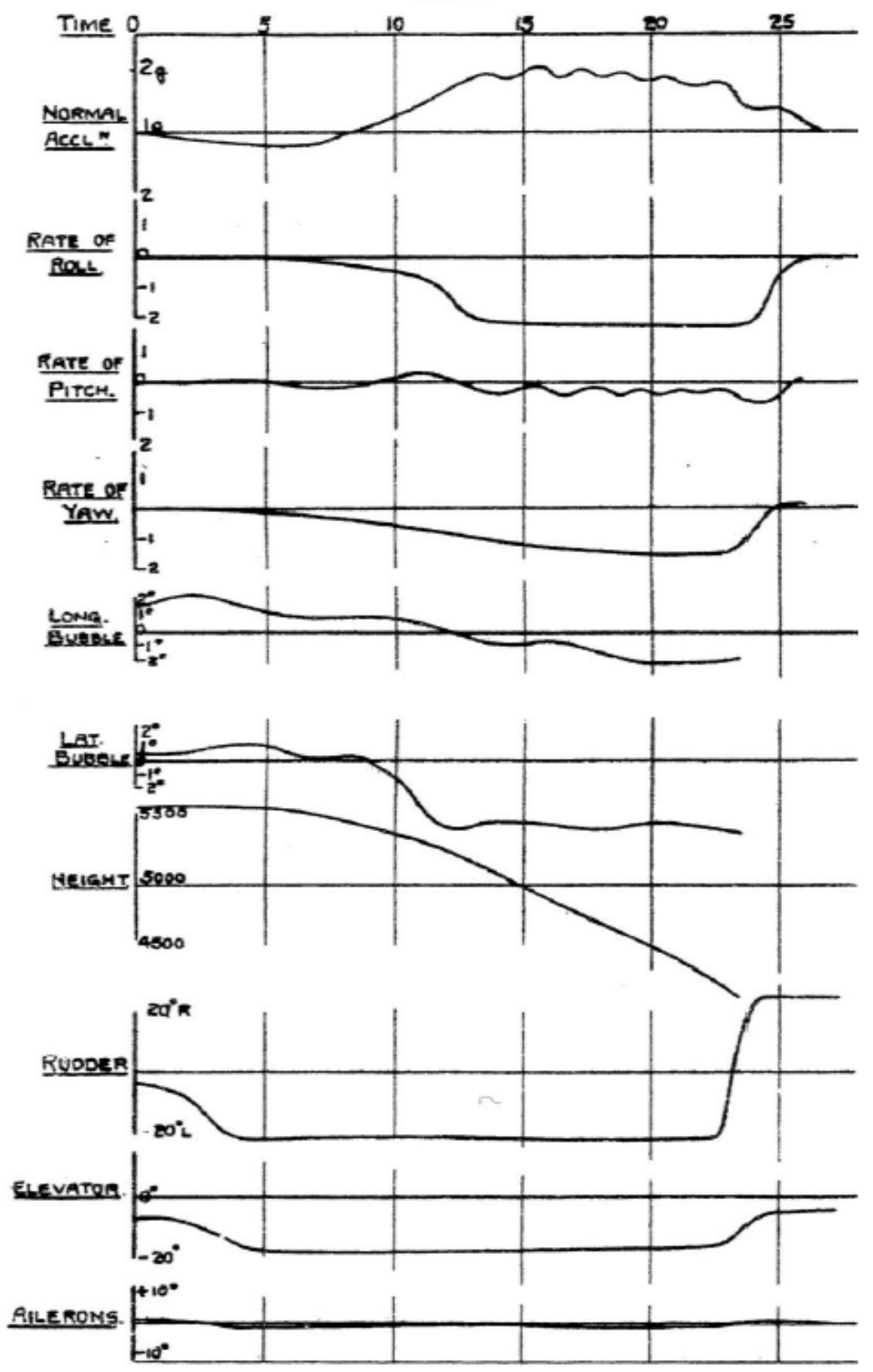

Figure 9: Traces of 11 parameters from Wright's spin trials in a Bristol Fighter [36]. 


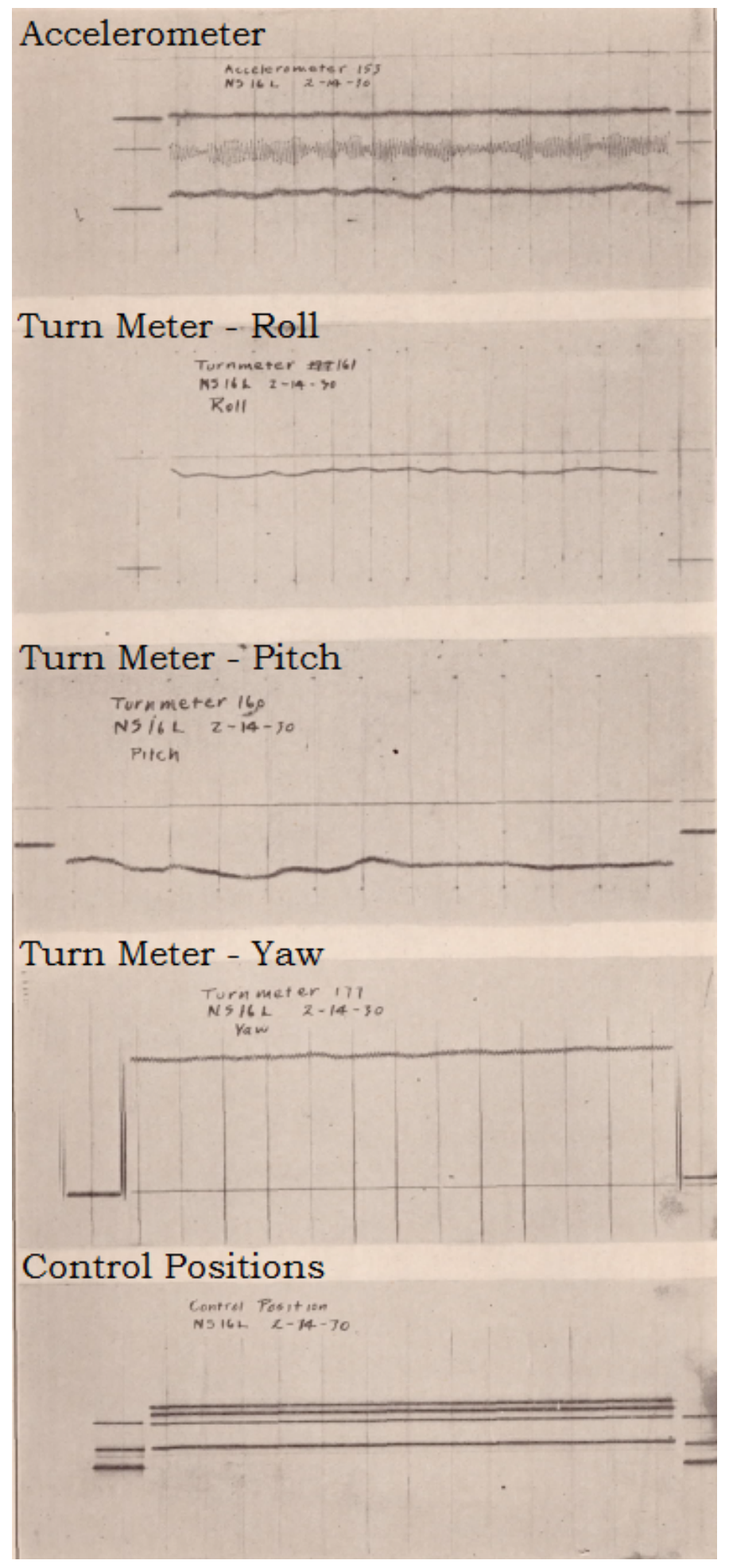

Figure 10: Traces of normal acceleration, roll rate, pitch rate, yaw rate, and control positions (top to bottom) for an example NY-1 biplane spin trial 37 . 
with analysis of a more modern aircraft [42] where it is concluded that the change in moments of inertia, due to altering the position of ballast (or fuel quantity in the case discussed later), is dominated by the much more significant masses which make up the aircraft, such as the engine.

Scudder, in collaboration with Seidman, next went on to investigate the spin characteristics of a F4B-2 biplane which had a reputation for dangerous spin tendencies [40]. The goal was to refine the tail section design to eliminate these unpredictable characteristics. Using the same set of NACA instruments, a number of tail section designs were spin tested, see Fig. 11. Again, in pure experimental fashion, a parachute was attached to the tail of the aircraft to aid recovery should the pilot find himself in an uncontrollable spin. Amongst other useful conclusions, it was noted that increasing the fin area and raising the horizontal tail surfaces had the greatest effect in aiding spin recovery. Comparison to spinning-balance model tests solidified these quantitative findings. Similar conclusions were also made by further NACA studies [43, 44] following the war.

The NACA work from this period was summarised in an extensive paper by Berman who documented the scale model test results from the spin tunnel at the Langley Research Centre, compared to flight test results, for 60 aircraft [45]. It was concluded that the scale model testing satisfactorily predicted characteristics of the spin in roughly 9 out of 10 cases. However, there were some discrepancies in angle of attack during the spin, depending on whether the model predicted an angle of attack greater than or less than $45^{\circ}$, as well as differences in the spin frequency depending on the tail-damping ratio. Furthermore, the models tended to lose less altitude per revolution than the actual aircraft.

Back in Britain, the immediate post war period saw flight testing of spinning continue briefly, perhaps evaluating aircraft designs which were rushed through the development cycle to help the war effort as quickly as possible. Kerr, an RAF pilot in World War 2, but by this time a fellow of the Royal Aeronautical Society, conducted a number of flight test investigations of Balliol Mk 2 [46, 47] and the Percival Provost aircraft, including perhaps the first flight test studies of the inverted spin [48, 49]. The tests provided valuable information regarding the spin characteristics in both the normal and inverted attitudes, advice on recovery techniques, and data to be fed into the derivation of a new theoretical model. Although the spins showed oscillatory behaviour in a number of parameters, as seen in earlier flight tests, this was attributed to the rising wing tip continually stalling and un-stalling. It was found that this behaviour could be subdued by applying aileron against the spin direction, or by applying down elevator. In general, the spins displayed characteristically high angles of attack, between 21.5 and $52^{\circ}$, and also typical spin frequencies of 0.31 to $0.57 \mathrm{~Hz}$.

This period of flight testing had provided a detailed insight into the highly dynamic nature of the spin. It was shown that several parameters often oscillated even during the developed, 'stable' stage of the spin. As it will be shown in Section IV, this behaviour is characteristic of more modern aircraft too. The spin frequencies and spin radii seen in the early flight tests summarised above, are also fairly typical of those seen on a more recent aircraft design, despite the tendency to favour mono- over bi-plane design in later years.

\section{LATER DEVElopments}

Throughout the remainder of the 1950's, flight testing of the aircraft spin was on the decline, due to the loss of interest in highly dynamic flying, post war. Now, spin investigations began to rely more heavily on scale model testing. In particular, the 15- and 20-foot free spinning tunnel 

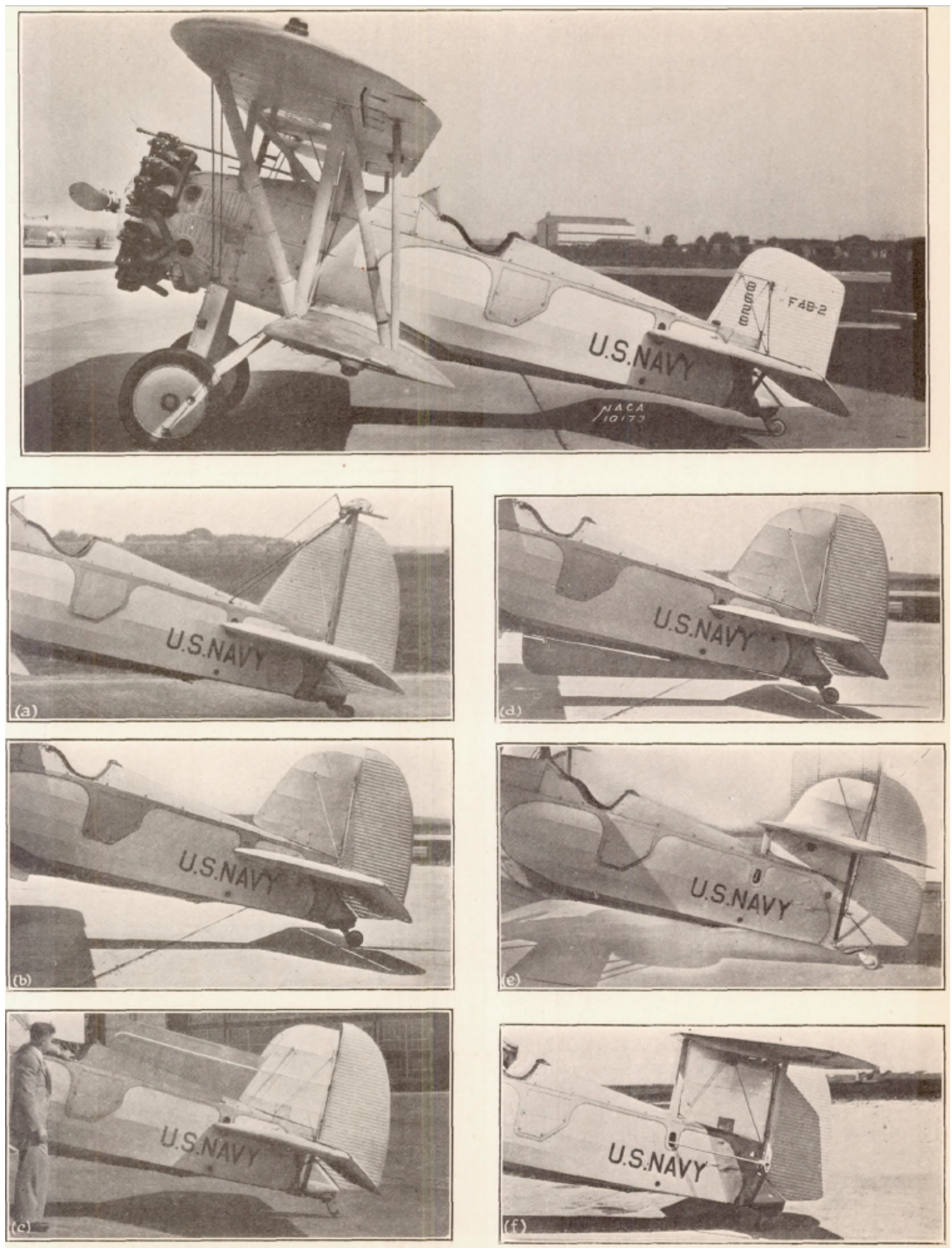

Figure 11: Various tail section designs analysed for ease of spin recovery [40]. 
facilities at NACA's Langley Air Force Base in Hampton Virginia was used extensively. Results of tests for 111 aircraft types are summarised by Malvestuto et al. [50] who concluded that the four main factors which affect the spin characteristics are the relative distribution of mass between the wing and the fuselage, the position of the centre of gravity, the relative density of the aircraft with respect to the air density, and the aircraft's tail section design. It was also concluded that for single engined aircraft, where the mass of the aircraft is distributed predominantly longitudinally, the rudder was the primary recovery control, although use of the elevator may help in certain situations. However, for multi engined aircraft where significant mass is distributed outboard from the fuselage, the elevator becomes the predominant control for recovery. Hence, wing loading was shown to have significant effect on the aircraft's spin characteristics and recovery response, as was earlier shown to be the case for a single engined bi-plane [38]. Later, summarising all NACA and NASA research regarding G-A light aircraft spinning, Bowman [3] also identified the mass distribution, including specific reference to the external wing tanks, as one of the key factors in defining the characteristics of a spin, in agreement with Malvestuto et al. [50].

The 1970's saw the emergence of increasingly experimental aircraft designs. However, this radical new era of aviation inevitably coincided with an increase in the number of accidents, mainly attributed to stalling and spinning. Stall and spin research therefore intensified once again, predominantly in military institutions. Scale model and theoretical investigations led to a number of significant breakthroughs. For example, a number of spin studies were conducted regarding jet aircraft [51, 52, [53] and delta wing designs [54, [55], sometimes now using remote control models [56].

By the time Rutan presented results from spin flight tests in a US Air Force F-4E Phantom II fighter in 1970, technology had reached the stage where data from the equipment on board could be telemetered to ground control. This allowed the test program to be monitored and managed from the ground with live updates communicated to the pilot via radio transmission. Two video cameras positioned over the pilots shoulder and on top of the fuselage also provided a unique insight.

This period also corresponded with the increased use of booms, in an attempt to record the angle of attack and sideslip angle during a spin. Canneday [57] demonstrated the accuracy of the angle of attack, sideslip, and airspeed recordings at a rate of $20 \mathrm{~Hz}$ from a simple boom (see Fig. 12) extended out from the wing tip of a low wing, single engined, light aircraft. The readings were corrected for upwash and transformed to the aircraft's center of gravity position, however the instrument often showed lag in it's response to rapid changes in flight condition.

A miniature air data sensor, see Fig. 13, as utilised by Kershner in his spin tests of radio controlled scale model aircraft [58], was able to record an extended range of flow angles: \pm $120^{\circ}$ for the angle of attack, and $\pm 55^{\circ}$ for the sideslip angle. The sensor was fitted to a nose boom, and was reported to be accurate to within approximately $0.35^{\circ}$ for angle of attack, $0.25^{\circ}$ for sideslip angle, and $1 \mathrm{~m} / \mathrm{s}$ for the airspeed. The sensor also demonstrated rapid dynamic response, demonstrating an improvement on the boom used by Canneday [57].

In 1980, Chambers [59] reviewed recent milestone developments in stall and spin flight test technology, as well as perfectly summarising the previous decades work, see Table 1 He reported that "great strides in flight procedures and instrumentation have been made in last decade" with new, innovative instrumentation now able to record: true airspeed and flow angles at each wing tip, accelerations and angular rates about body axes, control position and forces, engine parameters, altitude, parachute loads, telephoto video and movie ground camera coverage, and wing tip and cockpit mounted movie cameras. It was also noted that due to the miniaturisation 


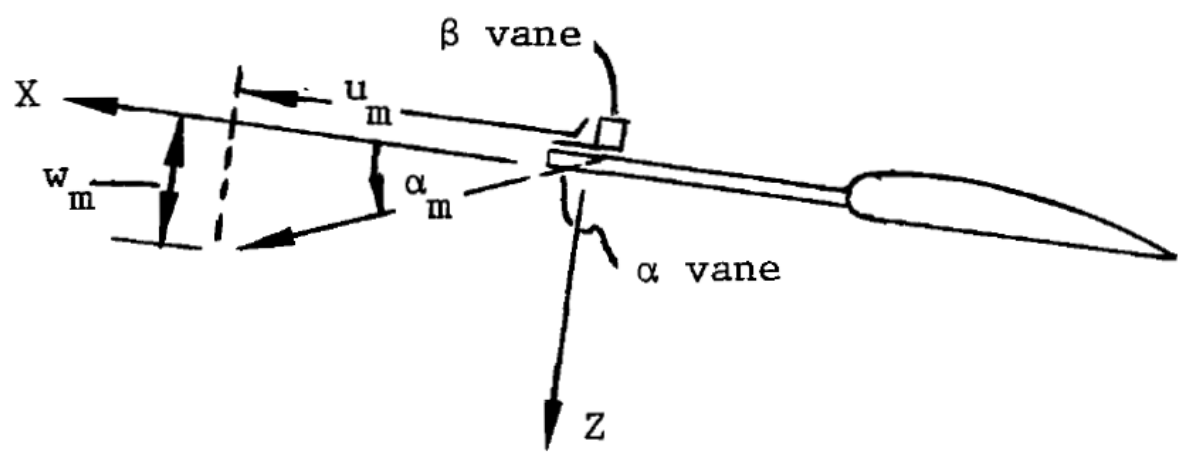

Figure 12: Simple air data boom as used in the flight tests by Cannaday [57].

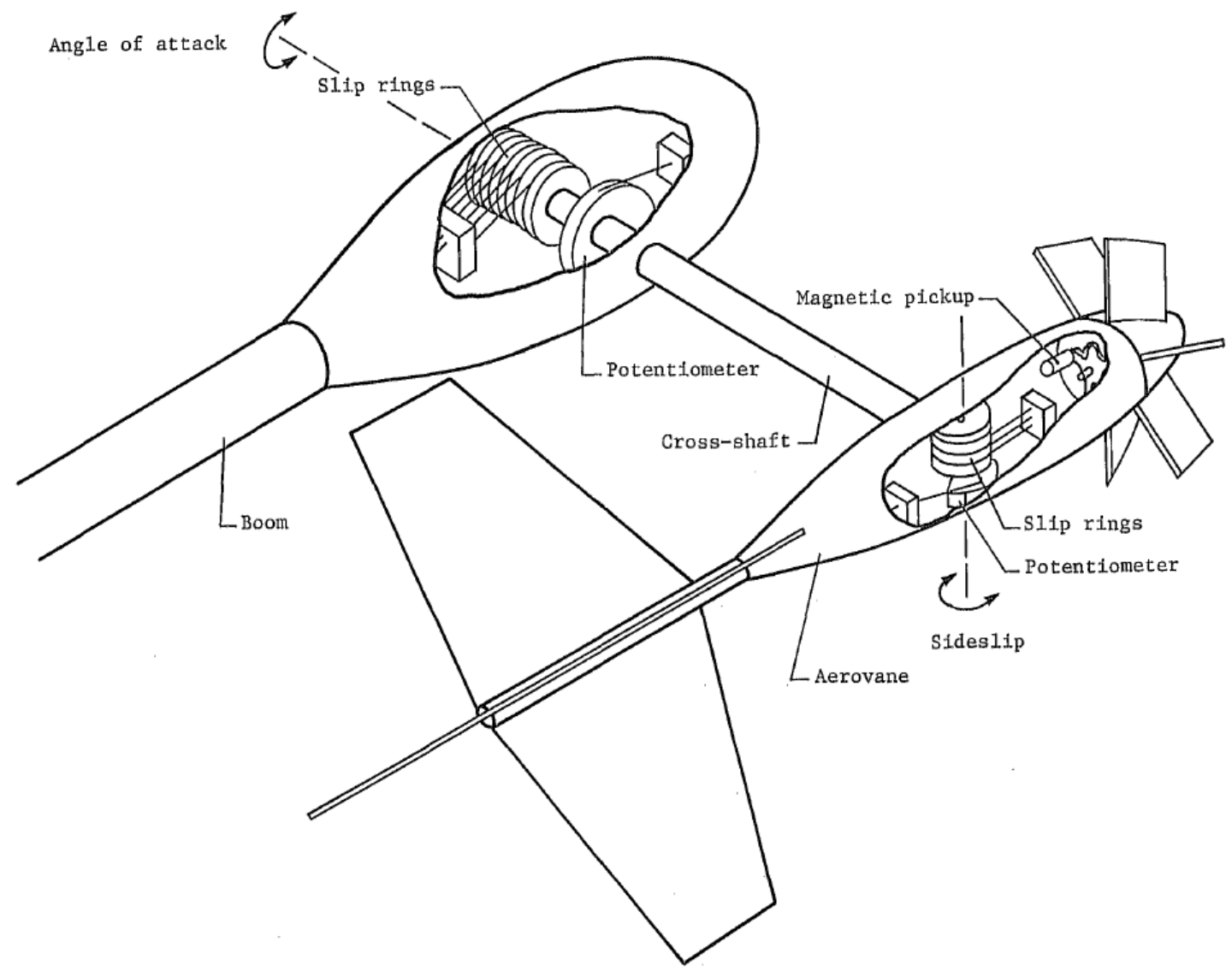

Figure 13: Air data sensor used in the scale model tests by Kershner [58]. 


\begin{tabular}{|c|l|}
\hline Decade & Activity \\
\hline $1900-1910$ & $\begin{array}{l}\text { Hazards of stall/spin experienced. } \\
\text { Elementary factors not understood. }\end{array}$ \\
\hline $1910-1920$ & $\begin{array}{l}\text { Spin recovery technique demonstrated. } \\
\text { Spin used as tactical manoeuvre in WWI. }\end{array}$ \\
\hline $1920-1930$ & Beginning of analytical studies and dynamic wind tunnel testing. \\
\hline $1930-1940$ & $\begin{array}{l}\text { Flight-test methods developed. } \\
\text { Height of pre-war research activity. }\end{array}$ \\
\hline $1940-1950$ & $\begin{array}{l}\text { WWII dominates resources. } \\
\text { Specific designs rapidly checked. } \\
\text { Little fundamental research. }\end{array}$ \\
\hline $1950-1960$ & Low point of research due to disinterest in highly manoeuvrable airplanes. \\
\hline $1960-1970$ & Increase in in military stall/spin accidents spurs intense research. \\
\hline $1970-1980$ & $\begin{array}{l}\text { Highest international activity in history. } \\
\text { High interest in highly manoeuvrable military airplanes } \\
\text { and general aviation safety. }\end{array}$ \\
\hline
\end{tabular}

Table 1: Summary of spin research 1900 - 1980 [59].

of much of the equipment, the effect on the aircraft's aerodynamics was minimal. Chambers goes on to describe revolutionary flight test methods for spin investigations regarding military fighter aircraft, including the use of compact hydrogen peroxide thruster rockets mounted on wing tips. These rockets, controlled by the pilot, could produce moments about the yaw and roll body axes to augment or oppose the moments generated in a spin. This facilitated two purposes. Firstly, to be used to aid recovery should the pilot find himself in an uncontrollable spin, as opposed to using a parachute affixed to the tail of the aircraft. Secondly, the rockets could be fired during a steady state spin to excite other modes, for example higher spin rates or angles of attack. Chambers also comments on the development of the first stall prevention systems, although at this time only available on military aircraft.

In recent years, despite an observed lull in flight testing focusing specifically on the spin, further refinement and miniaturisation of equipment means that flight test capability is more accurate and wider ranging than ever. For example, the miniature 7-hole probe air data system, used for spin testing by $\mathrm{Li}$ et al., is just $4 \mathrm{~mm}$ in diameter and weighs only $150 \mathrm{~g}$ but is still capable of measuring air flow angles to an accuracy of 1\% 60]. Similarly, an SBG Systems IG-500A Attitude and Heading Reference System (AHRS), utilised in studies regarding a Scottish Aviation Bulldog [61, 42], weighs just 39g, but can provide 3-dimensional attitude and acceleration data in a dynamic manoeuvre accurate to within $2^{\circ}$ [62]. Advances in technology such as these allows representative data to be gathered with minimum impact of the added equipment on the aircraft's centre of gravity, total weight, and general aerodynamics.

\section{Current State of Flight Test Research}

There are a number of newly developed flight test techniques which may be utilised in future spin research. For example, the AIM (Advanced In-flight Measurement) and $\mathrm{AIM}^{2}$ projects developed 
optical measurement techniques for flight testing such as fibre optic sensors for pressure and strain measurements, Light Detection and Ranging (LIDAR) for remote measurement of wind velocity, Image Pattern Correlation Techniques (IPCT) for surface deformation measurements, and Infrared Thermometry (IRT) and Particle Image Velocimetry (PIV) for air flow visualisation.

Firstly, Lawson et al. [61, 63] describes the development of the fibre optic sensors for flight test measurements of surface strain and unsteady pressure, using a Scottish Aviation Bulldog. Fibre Bragg gratings (FBGs), distributed along the port side wing were used to record wing strain data. FBGs are periodic modulations of the refractive index of the fibre optic core. They are typically fabricated by illuminating the core with ultra-violet (UV) light through a phase mask. The FBGs then effectively act as reflectors, allowing the measurement of the Bragg grating period, through either transmitted or reflected light passed through the fibre. As the wing is under strain during flight, the fibres bend to deform the gratings, leading to a change in detected wavelength. In these tests, a second fibre optic sensor, a Fabry-Perot (FP) sensor, was used to record surface pressure fluctuations. The FP sensor consists of an optical fibre and a reflective diaphragm, which forms an optical cavity. As the pressure changes on the diaphragm, the movement of the diagphram can be measured interferometrically using a scanning laser to illuminate the fibre. In both cases, the fibre optic sensor data was recorded by a SmartScan Aero Interrogator box inside the cockpit. Laboratory calibrations allowed the recorded wavelength and intensity data to be converted into strain and pressure measurements respectively, following the flight tests. The study also utilised other equipment such as an independent Kulite pressure sensor and an AHRS, as mentioned above, to cross check the fibre optic sensors and also to correlate attitude and acceleration data with the fibre optic data.

The performance of the fibre optic sensors was verified by Lawson et al. [61, 63] before the same instrumentation was used in a further study regarding the effect of mass distribution on the characteristics of a spin [42]. The tests involved altering the fuel load on board to identify the changes in moments of inertia during a spin. It was found that the aircraft spins $4-5 \%$ faster with a low fuel load than with a high fuel load, and the yawing effect of the propeller causes the aircraft to spin approximately $1.6 \%$ faster to the right than to the left. These minor differences were captured due to the high sample rates and fine resolution of the fibre optic equipment.

Secondly, although not new technology, the increasing availability of LIDAR systems allowed Augere et al. [64] to develop a laser anemometer. This technique uses a single frequency laser, projected from on-board an aircraft, to reflect a light wave from natural aerosols in the atmosphere, through Mie scattering. An interfermometer detects the reflected signal and measures the frequency shift compared to a reference wave. The frequency shift is proportional to the air velocity in the freestream. Therefore, using this method, it is possible to measure air speed, angle of attack, and sideslip angle in the freestream. This technique was shown to be accurate to $1 \mathrm{~m} / \mathrm{s}$ for the true airspeed, and to $0.5^{\circ}$ for the flow angles in a study by Augere et al. [64] based on flight test results using a Piaggio P180. A 3-axis wind LIDAR was also used on-board a Dauphin 6075 helicopter to show that the direct measurement of true airspeed is possible by considering the airflow outside of the influence of the helicopter rotors [65].

Flight test studies by Rzucidlo et al. [66, 67], also part of the AIM project, used a PW-6U glider to test IPCT and IRT methods. IPCT uses a camera to observe an object covered with a random pattern. If the object changes shape or deforms, the the image of the random pattern is compared to the reference image of the same object, allowing displacement vectors to be calculated, see Fig. 14 IRT, uses a thermographic camera to observe infrared radiation from a surface, allowing the surface temperature distribution to be visualised to a high degree of accuracy. IRT allows inves- 

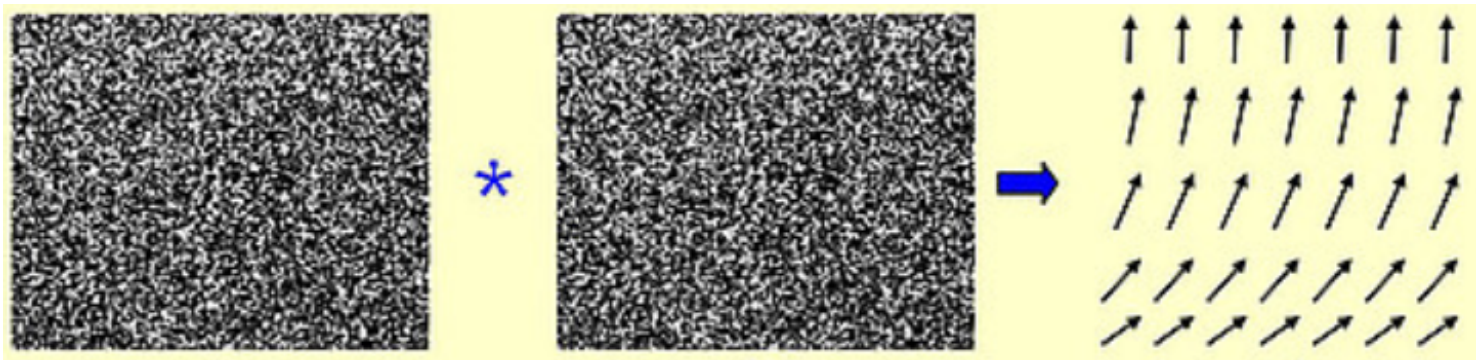

Figure 14: Example of how the deformed image (centre) is compared to the reference image (left) to generate the displacement vectors (right) in IPCT [68].

tigation of the boundary layer on an aircraft wing, specifically, the laminar-turbulence transition features may be identified due to the jump in the wall shear stress coefficient and hence the heat transfer coefficient. The flight tests by Rzucidlo et al. demonstrated the capabilities of both the IPCT and IRT techniques in a flight test environment, as well as how the data could be synchronised with standard flight test equipment using a time stamp from a GPS system. The methods enabled visualisation of the airflow around the wing and also the boundary layer development, during both the stall and during operation of the glider's air brake. However, illumination by the sun in some circumstances, and the heat capacity of the wing material, did present challenges in observing these details.

Finally, PIV has been extensively tested by a research group at the German Aerospace Centre (DLR) Institute of Aerodynamics and Flow Technology for in-flight flow measurement and visualisation [69, 70, 71, 72]. PIV in flight, in it's simplest form, illuminates natural aerosols in the atmosphere with a pulsed laser light sheet and the scattered light of the particles is recorded with two stereoscopic cameras. This set-up allows all three components of the velocity field in a plane to be visualised. In the flight test studies by the DLR group, the PIV method was used to capture the velocity vector field behind the wing of a Dornier DO 228-101 aircraft, see the example given in Fig. 15. Analysing the results, it was found that boundary layers, shock waves, and vortices may all be observed using this method.

It is clear that new technology, as investigated by the AIM projects in particular, can potentially offer new insight into complex aerodynamic characteristics of aircraft in flight. The newly developed techniques may provide the next step into fully understanding spin dynamics. According to the most recent literature, the future of airborne measurement appears to be focusing on the continuing development of techniques in optics and photonics [73].

\section{FinAl Remarks}

An extensive review into the development of flight test equipment and methodology, from the very beginnings of aviation up to the modern day, is presented. Key developments are highlighted and the contribution of the results are put into context of aviation history.

The first observation which should be made, is that despite the considerable differences in aircraft design from the light-weight bi-planes of the 1920's up to the relatively modern aerobatic and training aircraft used for later studies, features of the aircraft spin are remarkably similar. Almost every documented spin trial analysed for this review has a frequency of $0.3-0.7 \mathrm{~Hz}$, an 


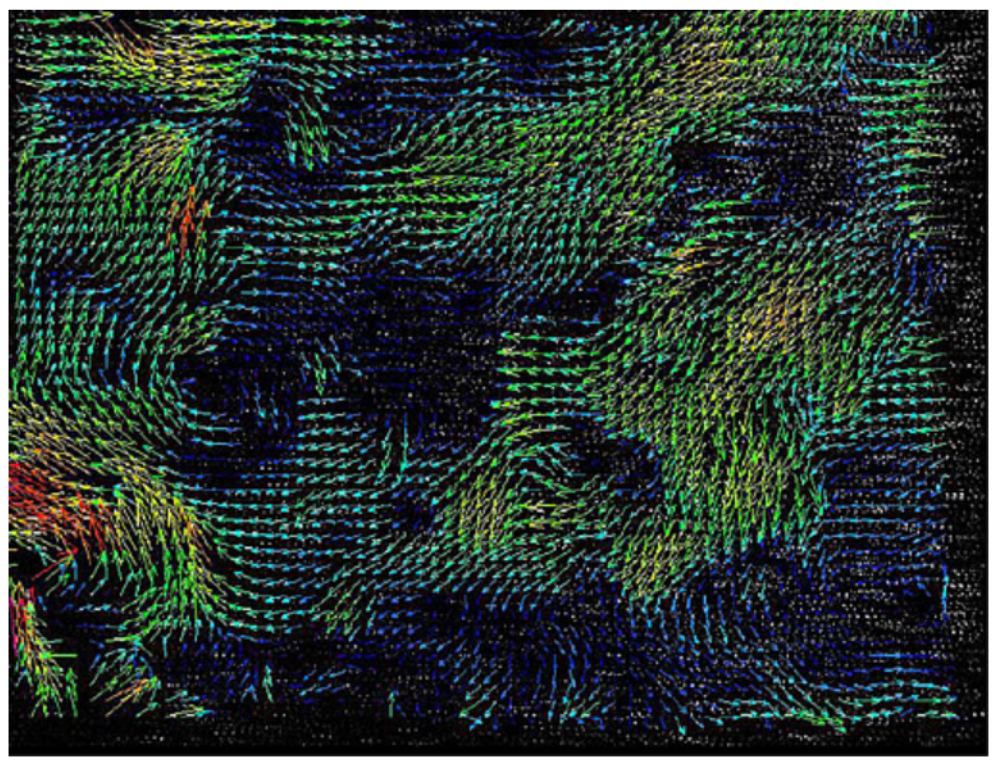

Figure 15: Example velocity vector field measured using PIV [68] in the study by Politz et al. [72].

angle of attack range of $25-70^{\circ}$, and a radius of approximately $1-3 \mathrm{~m}$. Furthermore, despite the radical improvements in design to improve an aircraft's predictability and controllability during a spin, a number of key parameters continue to oscillate throughout the fully developed stage.

Flight test technology has now reached the stage where commercial-off-the-shelf (COTS) equipment can provide a higher degree of accuracy than any bespoke equipment developed previously, demonstrating the continuing improvement and miniaturisation of on-board equipment. With the further development of new technology, new insights into the aircraft spin continue to emerge.

Despite this, it appears that with each new investigation into spinning, although offering ever greater accuracy, results continue to validate the fundamental qualitative results of the 1920's, rather than discredit or disprove these early findings. It seems appropriate therefore to acknowledge the early pioneers of the field, many of whom risked their lives for the advancement of knowledge in this area. The ingenuity and perseverance shown in this period deserves significant acclaim.

Finally, it is important to acknowledge the impact of spin research in the wider context of aviation. Advances in aircraft design for performance, efficiency, and safety, all owe in some part to the flight test studies conducted to investigate the spin. Furthermore, knowledge of aerodynamic theory in high angle of attack and stall conditions has also been accelerated. It is also clear that the way in which experimental research is conducted today, as compared to the early days of aviation, has been aptly demonstrated by this review. It is apparent that the prioritisation of safety, cost, and application of flight test studies, was not always given the forethought that it is today. 


\section{REFERENCES}

[1] R. D. Kimberlin. Flight Testing of Fixed Wing Aircraft. AIAA Educations Series. AIAA, Virginia, USA, 2003.

[2] D. T. Ward and T. W. Strganac. Introduction to Flight Test Engineering. Kendall/Hunt Publishing Company, Iowa, USA, 2 edition, 1998.

[3] J. S. Bowman. Summary of spin technology as related to light general aviation airplanes. NASA Technical Note, (TN D-6575):619 - 688, 1971.

[4] J. Collins and A. (Eds.) Sable. Stall and spin accidents: Keep the wings flying. AOPA Air Safety Institute, 20157.

[5] Aircraft Owners and Pilots Association. Stall-spin: Entry point for crash and burn? https://www.aopa.org/asf/ntsb/stall_spin.html. Accessed: 2018-02-05.

[6] B. J. Brinkworth. On the early history of spinning and spin research in the UK, Part 1: the period 1909-1929. Journal of Aeronautical History, (2014/03), 2014.

[7] Various. Report of the committee for the year 1909-10. Advisory Committee for Aeronautics, (Cd 5282), 1910.

[8] A. E. Berriman. Parke's dive. Flight, 4:787 - 788, 1912.

[9] F. A. Lindemann, H. Glauert, and R. G. Harris. The experimental and mathematical investigation of spinning. Advisory Committee for Aeronautics, (ACA R\&M 411), 1918.

[10] H. Glauert. The rotation of an aerofoil about a fixed axis. Advisory Committee for Aeronautics, (ACA R\&M 595), 1919.

[11] H. Glauert. The investigation of the spin of an aeroplane. Advisory Committee for Aeronautics, (ACA R\&M 618), 1919.

[12] H. B. Irving, A. S. Batson, H. C. H. Townsend, , and T. A. Kirkup. Experiments on a model of a BAT Bantam aeroplane with special reference to spinning accidents, Parts 1 and 2. Aeronautical Research Committee, (ARC R\&M 976), 1925.

[13] H. B. Irving and A. S. Batson. Further experiments on a model of the "Bantam" aeroplane, with special reference to the "flat" spin. Aeronautical Research Committee, (ARC R\&M 1107), 1927.

[14] Stability and Control Panel. The lateral control of stalled aeroplanes. Aeronautical Research Committee, (ARC R\&M 1000), 1925.

[15] S. B. Gates and L. W. Bryant. The spinning of aeroplanes. Aeronautical Research Committee, (ARC R\&M 1001), 1926.

[16] J. A. G. Haslam. Wool tufts. Aeronautical Research Committee, (ARC R\&M 1209), 1928.

[17] B. M. Jones and J. A. G. Haslam. Airflow about stalled and spinning aeroplanes shown by cinematographic records of the movements of wool-tufts. Aeronautical Research Committee, (ARC R\&M 1426), 1932.

[18] A. F. Zahm. Development of an airplane shock recorder. Journal of the Franklin Institute, 1919.

[19] Various. On the theory of speed indicators. Rapports do Premier Congres International de la Navigation Aerienne, 1921.

[20] F. H. Norton. NACA recording airspeed meter. NACA, (TN-64), 1921.

[21] F. H. Norton and E. T. Allen. Accelerations in flight. NACA, (99), 1921.

[22] F. H. Norton and E. P. Warner. Accelerometer design. NACA, (100), 1921.

[23] F. H. Norton. Control position recorder. NACA, (TN-97), 1922. 
[24] J. K. Hardy. Full scale control tests on Fokker F.7 3M monoplane. Aeronautical Research Committee, (ARC R\&M 1228), 1928.

[25] H. J. E. Reid. A study of airplane manoeuvres with special reference to angular velocity. NACA, (TR-155), 1922.

[26] H. J. E. Reid. The NACA three-component accelerometer. NACA, (TR-112), 1922.

[27] W. G. Brown. The synchronization of NACA flight records. NACA, (TR-117), 1922.

[28] K. M. Ronan. An instrument for recording the position of airplane control surfaces. NACA, (TR-154), 1923.

[29] F. G. Nesbit. Tests of air corps type D-4 altimeter. Air Corps, (TR-3153), 1929.

[30] T. Hubner and W. Pleine. Cinematographic measurements of an albatros L-68 in a spin. Zeitschrift fÃijr Flugtechnik und Motorluftschiffahrt, pages 29-38, 1929.

[31] P. Raethjen. Remarks on the motion of a spin and its cinematographic measurement in flight. Zeitschrift fur Flugtechnik und Motorluftschiffahrt, pages 413-423, 1929.

[32] H. B. Irving, A. S. Batson, and A. V. Stephens. Spinning experiments on a single seater fighter with deepened body and raised tailplane, Part I: Model experiments and Part II: Full scale spinning tests. Aeronautical Research Committee, (ARC R\&M 1421), 1931.

[33] D. Jones and H. L. Stevens. The RAE control movement recorder - Mark III. Aeronautical Research Committee, (ARC R\&M 942), 1924.

[34] G. T. R. Hill. Flying positions of control surfaces of a Bristol Fighter. Aeronautical Research Committee, (ARC R\&M 1060), 1926.

[35] B. M. Jones and C. E. Maitland. Instrumental records of the lateral motions of a stalled Bristol Fighter aeroplane - an account of experiments carried out in the Cambridge University Air Squadron. Aeronautical Research Committee, (ARC R\&M 1181), 1928.

[36] K. V. Wright. Experiments on the spinning of a Bristol Fighter aeroplane. Aeronautical Research Committee, (ARC R\&M 1261), 1929.

[37] H. A. Soule and N. F. Scudder. A method of flight measurement of spins. NACA, (TR-377), 1931.

[38] N. F. Scudder. A flight investigation of the spinning of the NY-1 airplane with varied mass distribution and other modifications, and an analysis based on wind tunnel tests. NACA, (TR-441), 1934.

[39] N. F. Scudder. A flight investigation of the effects of mass distribution and control setting on the spinning of the XN2Y-1 airplane. NACA, (TR-484), 1934.

[40] N. F. Scudder and O. A. Seidman. A flight investigation of the spinning of the F4B-2 biplane with various loads and tail surfaces. NACA, (TR-529), 1935.

[41] M. Scherberg and R. V. Rhode. Mass distribution of free flight models. NACA, (TN-268), 1927.

[42] The aircraft spin - a mathematical approach and comparison to flight test, Denver, CO, June 2017. ARC.

[43] A. I. Neilhouse, J. H. Lichtenstein, and P. W. Pepoon. Tail design requirements for satisfactory spin recovery. NACA, (TN-1045), 1946.

[44] W. J. Kilnar and T. L. Snyder. Influence of tail length upon the spin recovery characteristic of a trainertype airplane model. NACA, (TN-1764), 1948.

[45] T. Berman. Comparison of model and full-scale spin test results for 60 airplane designs. NACA, (TN-2134), 1950.

[46] T. H. Kerr and D. R. Dennis. Model and full scale spinning tests of a conventional straight wing aircraft (Balliol Mk 2). RAE Aero Report, (2480), 1953.

[47] T. H. Kerr. An investigation of spin and recovery characteristics of a conventional straight wing aircraft. RAE Aero Report, (2509), 1954. 
[48] T. H. Kerr. Full scale spinning tests on the Percival Provost Mk1 including the inverted spin. ARC, (CP-240), 1955.

[49] T. H. Kerr. Full scale spinning tests on the Percival Provost Mk2 including the inverted spin. ARC, (CP-240), 1956.

[50] F. S. Malvestuto, L. J. Gale, and J.H Wood. Compilation of test data on free spinning airplane models tested in the Langley 15-foot and 20-foot free-spinning tunnels. NACA, (L7E15), 1947.

[51] D. R. Dennis. Model spinning tests on a jet trainer (Macchi MB 326). RAE Aero Technical Note, (2489), 1956.

[52] D. R. Dennis. Model spinning tests on a jet research aircraft. RAE Aero Technical Note, (2684), 1960.

[53] J. R. Chambers, J. S. Bowman, and E. L. Anglin. Analysis of the flat spin characteristics of a twin-jet swept-wing fighter airplane. NASA, (TN D-5409), 1969.

[54] J. S. Bowman. Spin entry characteristics of a delta wing airplane as determined by a dynamic model. NASA, (TN D-2656), 1965.

[55] R. Wilson. Analytical investigation of spinning behaviour and recovery from a developed spin of a 60 deg delta wing aircraft configuration using a high speed digital computer. WRE, (TN HSA-137), 1968.

[56] W. Bihrle. Correlation study of theoretical and experimental results for spin tests of $1 / 10$ th scale radio control model. NACA, (CR-144995), 1976.

[57] R. L. Cannaday and W. T. Suit. Effects of control inputs on the estimation of stability and control parameters of a light airplane. NASA, (TP-1043), 1977.

[58] D. D. Kershner. Miniature flow-direction and airspeed sensor for airplanes and radio-controlled models in spin studies. NASA, (TP-1467), 1979.

[59] J. R. Chambers. Overview of stall/spin technology. AIAA, (80-1580), 1980.

[60] S. Li, Y. Gu, J. Han, and Q. Wang. A miniature seven-hole probe air data system and its application on spin prediction. International Journal of Micro Air Vehicles, 8(3):143-154, 2016.

[61] N. J. Lawson, R. Correia, S. W. James, M. Partridge, S. E. Staines, J. E. Gautrey, K. P. Garry, J. C. Holt, and R. P. Tatam. Development and application of optical fibre strain and pressure sensors for in-flight measurements. Measurement Science Technology, 27(10), 2016.

[62] N. Michel and A. Guinamard. Ig-500a sub-miniature AHRS user manual. SBG Systems, 2013.

[63] N. Lawson, R. Correia, S. James, J. Gautrey, G. Rubio, S. Staines, M. Partridge, and R. Tatam. Development of the cranfield university bulldog flight test facility. Aeronautical Journal, 121:533-552, 2017.

[64] B. Augere, B. Besson, D. Fleury, D. Goular, C. Planchat, and M. Valla. 1.5 $\mu \mathrm{m}$ Lidar anemometer for true air speed, angle of sideslip and angle of attack measurements onboard Piaggio P180 aircraft. Measurement Science and Technology, 27(054002), 2015.

[65] All-fiber 1.5 $\mathrm{m} \mathrm{CW}$ coherent laser anemometer DALHEC, kamakura, Japan, 2005. Helicopter flight test analysis.

[66] P. Rzucidlo, G. Kopecki, A. Kucaba-Pietal, R. Smusz, M. Swewczyk, M. Szumski, and K. de Groot. Data acquisition system for PW-6U in flight boundary layer mapping. Aircraft Engineering and Aerospace Technology, 88, 2015.

[67] G. Kopecki and P. Rzucidlo. Integration of optical measurement methods with flight parameter measurement systems. Measurement Science and Technology, 27(054003), 2016.

[68] German Aerospace Centre (DLR). Aim Project Website - Measurement Techniques, April 2018.

[69] Particle Image Velocimetry for In-Flight Application - Preparation, Test and Lessons Learned, Daegu, Korea, June 2010. 
[70] In-flight flow visualisation using Particle Image Velocimetry, Lisbon, Portugal, July 2010.

[71] C. Politz, N. Lawson, R. Konrath, J. Agocs, and A. SchrÃúder. evelopment of Particle Image Velocimetry for In-Flight Flow Measurement. Springer, Verlag, Heidelberg, New York, Dordrecht, London, 2013.

[72] Free Flight Boundary Layer Investigations by means of Particle Image Velocimetry, Lisbon, Portugal, 2014.

[73] R. Sabatini, M. Richardson, A. Gardo, and S. Ramasamy. Airborne laser sensors and integrated systems. Progress in Aerospace Sciences, 79:15-63, 2015. 
2018-06-29

\section{On the development of flight-test equipment in relation to the aircraft spin}

Bennett, Christopher J.

Elsevier

C.J. Bennett, N.J. Lawson, On the development of flight-test equipment in relation to the aircraft spin, Progress in Aerospace Sciences, Volume 102, Issue October, 2018, pp. 47-59

https://doi.org/10.1016/j.paerosci.2018.06.001

Downloaded from Cranfield Library Services E-Repository 